\title{
Women and Communication: Mobile Apps and Women's Safety
}

\author{
Prof. Dr. Shirin Abbas
}

\begin{abstract}
The paper looks at the response and success of Helplines introduced to stem violence against women in the background of the crime rates in the state of Uttar Pradesh. A number of mobile apps have surfaced like Police and Women's helplines. This is a cross-gender study of the awareness of Women's helplines and efforts to reduce maternal mortality and provide better healthcare to women in the state through the use of Mobile Apps.

Helplines in Lucknow (U.P.) and one most backward district effective for women's safety?

he study aims to assess efficacy and use of Women's Helplines using quantitative analysis using a structured Interview Schedule and FGDs.
\end{abstract}

Keywords-Mobile Apps, Uttar Pradesh Women and Communication, Women's Safety, Women's Studies.

\section{INTRODUCTION}

"Women's progress is human progress" The Johns Hopkins University School of Advanced International Studies (SAIS) in 2014 held its Conference on Global Women in Leadership, which examined ways in which technology was providing new opportunities for women. The conference, entitled "Technology in Action: Changing the Way Women Live and Work," also focused on how women were taking advantage of the fact that technology is not only improving service delivery, but playing a major part in advancing their empowerment. ${ }^{1}$

In her keynote address at the conference, Kathy Calvin, CEO and president of the United Nations Foundation, stressed that, while the modern world was shrinking, opportunities were getting bigger. She also pointed out that that technology was a specific tool that provided opportunities to women. Technology, she averred, had paved the way for greater democratization and revolutionized services, from banking and finance to education and health. Ms Calvin also opined that the world was witnessing a power shift leading to ordinary citizens now proposing solutions: Bottom-up change was happening today more than ever. Technology, she felt, was the solution that would continue to empower girls and women and, for that reason, was vital for the future. Women's progress was in fact human progress, Calvin emphasized. ${ }^{2}$

Adding to this opinion, Dr. E. William Colglazier, science and technology adviser to the U.S. Secretary of State, stated that individual empowerment would accelerate owing to poverty reduction, global middle class growth, greater educational

Prof. (Dr.) Shirin Abbas, Institute of Media Studies, Shri Ramswaroop Memorial University). attainment, widespread use of new communications and manufacturing technologies, and health care advances. ${ }^{2}$

While transformative technology was not limited to information and communication technologies (ICTs) - it also included developments including new mobile technologies. Mobile phones and tools he felt had become popular worldwide, as in Africa. ${ }^{3}$ For example, M-Pesa, a mobile platform that had revolutionized access to banking in rural areas, was often quoted as a success story. Panelists at the event also cited initiatives like MAMA (which provided important information through text and voice messages to pregnant women), and M-Farm (which informed rural farmers of market prices for their crops, alerts them of good prices for inputs, and connects them to buyers), as important innovations for women.

These mobile technologies, he averred, could also offer women a stronger voice and more control, particularly in business. A report funded by ExxonMobil and the Cherie Blair Foundation argued that mobile phones with added services were the best tools for women's empowerment and for increasing women business owners' productivity. In fact, the survey argued that women micro-entrepreneurs believed in mobile solutions to challenges: 82 percent of women entrepreneurs surveyed were willing to pay for added services through mobile phones. ${ }^{4}$

Importantly, panelists at the event noted that there was still a substantial ICT gender gap in developing countries. The report also noted that one critical obstacle to women's access to mobile phones was affordability: Expensive ICTs were reserved for use by men, and women tend to get second-hand phones. Technology was viewed as a tool for men, so it seemed that culture and attitudes toward ownership of productive assets were still impediments to women's access to technology.

India has overtaken USA to become the second ranked Internet user worldwide, however penetration is still low at just around $28 \%{ }^{5}$ with $75 \%$ of usage limited to those age 35 and under. India ia also $3^{\text {rd }}$ among mobile users In the world as per the Device Atlas Q1 report $2016^{5}$ the total number of subscribers is estimated at 1035 million in March 2016 \& $1 \%$ pf users are reported to be males with females accounting for just $29 \%$ of Internet users. A NASSCOM - AKAMAI Technologies Report of August 2016 has predicted there will be $\sim 730$ million users in India by 2020 . $^{6}$

\section{HYPOTHESIS}

Uttar Pradesh, the most populous and considered backward state of India, is witnessing increased mobile usage and 
positive trends towards mobile and social media usage amongst women and for women's health and safety in the districts covered by the study. It is reported to have 35.61 million internet users by March $2016 .^{7}$

A review of literature led to the question whether the exponential growth in mobile usage is transcending the gender gap in communication or not in India's largest state of Uttar Pradesh. As the size and demographics of the state are impossible to encompass in one study, the researcher selected four most backward districts of Central Uttar Pradesh known for their poor development indices using the District Development Indices ${ }^{8}$, UNDP's Human Development Report ${ }^{9}$ and the Govt. of India's Planning Commission Uttar Pradesh: State Development Report (Vol I \& II) ${ }^{10}$

The researcher then embarked on an extensive 18 month survey (Interview Schedule) covering 500 respondents with mobile connections across the four selected most back districts of Central Uttar Pradesh namely Barabanki, Sitapur, Gonda and Rae Bareli to assess the usage patterns, awareness, gender gap in communication and examine whether there was a possibility to further propagate the awareness of social schemes and benefits of the same in areas related to Health, Education, Development, Women's Empowerment and Safety, Benefits of Government Outreach Initiatives and other such initiatives through use of social media applications.

Two villages were selected from each district and personal interviews conducted through a rigorous interview Schedule to ascertain the same. For this paper we use certain hand-picked variables from the doctoral research study of the scholar to ascertain whether there is sufficient awareness and usage of mobiles among rural women so as to empower them to reap the benefits of schemes instituted especially for women to positively impact their health and safety.

\section{BACKGROUND}

With every 6th Indian hailing from the state of Uttar Pradesh, in the vibrant scenario of Digital India ${ }^{11}$ it becomes important to assess the penetration and acceptance of mobile usage among women in the State. The crime scenario in Uttar Pradesh is the highest all over India. Nearly 11 per cent of the total crimes against women are reported from Uttar Pradesh. ${ }^{12}$ It is for this reason that certain private Helplines dedicated to general safety and women's safety, have been enforced in the state. Among these the top most are 100 - the Police Helpline which promises response to a victim within 20 minutes and the Women's Powerline 1090 which has effectively curbed eveteasing and harassment of women in the state. This study goes on to assert that State and private run mobile helplines are transforming lives of women across India's most populous and underdeveloped state of Uttar Pradesh known for its high maternal mortality rate, low levels of literacy and an inherent gender bias against women. The paper is based on the doctoral research of the author across four most backward districts of Central Uttar Pradesh. These include the districts of Barabanki, Rae Bareli, Gonda and Sitapur, all extremely backward areas of Uttar Pradesh, the state under review. The study covers over 500 respondents and tries to ascertain the knowledge and use of mobile helplines created for women's health and safety in the state.

\section{RESEARCH GAP AND LIMITATIONS}

As far back as 2009 there were clear trends emerging of growing demand of mobile phones from rural areas. However no concrete data/research was available on usage patterns, preference of mobiles over traditional communication tools etc. A clear research gap was thus visible with a need to study how the most powerful communication tool in recent times was impacting rural Uttar Pradesh.

The study is limited to rural mobile users in the four most backward districts of the Central Uttar Pradesh. It does not attempt a comparative study of the before and after effects of introduction of mobiles. However if the study can effectively prove substantive usage of mobiles in these areas, it would be safe to say that the results of the study can be applied to the entire state and considered applicable for all populations across the state.

\subsection{Type of Research:}

Unlike basic research, a form of social science research which is designed to add to one's knowledge and understanding of a social research, applied research is the path adopted here as practical results are produced which can be put into practice for policy making, aid in prompt and effective information disseminations and assist consultative process through its applicability. This descriptive study would make use of quantitative data analysis by addressing respondents through an Interview Schedule and collect and analyze their responses.

\subsection{Method of Data Collection:}

Secondary data in the form of Census $2011^{6}$ and District Development Indices ${ }^{8}$ were the two main reports used for data collection and build sampling structure. Primary data was collected through the Interview Schedule put across to over 500 respondents in eight villages of four most backward districts of Central Uttar Pradesh. A Structured Interview Schedule was used to ascertain responses from over 500 respondents across the four districts as a pilot study indicated the use of the same against a questionnaire for the largely rural population covered under the research. Also a need was felt to include a female interviewer to conduct interviews with women folk in rural areas as there were barriers to men communicating with women in the rural areas covered under the study.

\subsection{Research tool \& Reason for its Selection:}

An Interview Schedule was selected as the best tool to collect this data as a large number of the rural respondents under study were not literate with Social media being the independent variable and all other factors dependent on the use of Social Media and affected by the same serving as dependent variables to the study.

\subsection{Development of Research Tool:}

The research tool was constructed keeping in mind the core areas of Health, Education, Information Dissemination and 
Consultative Process, Rural Helplines, Women's Empowerment, Rural Employment Schemes, Agricultural Facilities, Monitoring of government and non-governmental helplines and services and ascertain acceptability of the same if traditional information dissemination was replaced by mobile technology and SMS/IVRS.

\subsection{Verification and pre-testing:}

Verification and pre-testing of the Interview Schedule was done on a selected sample to ascertain drawbacks and feasibility of the same. This yielded some significant results such as the need for the Interview Schedule to be in local language. It was also found that the males conducting the Interview Schedule met with many barriers in communicating with rural female population, thus it was felt advisable to include a female during the conduct of the same in villages. Verification and pre-testing was conducted on a small sample of prospective respondents. Need was felt to use the Interview Schedule in local language considering that most of the respondents belonged to rural areas and care had to be given to include local parlance to make the same easily understandable by them.

A need was felt to include a woman in the team conducting the Interview Schedule since access to women respondents was difficult for male interviewers, talking to strange men is still a social taboo in rural hinterlands of the state. There was also a need to induct a local with the interviewer for easy access to respondents.

\subsection{Sampling:}

Since the research was aimed to find out acceptability and penetration of mobile usage multi-stage purposive sampling was carried out of respondents using mobiles in the said areas to derive at a reasonable sample base for the study.

Stage I: Four Most Backward Districts of Central UP (Gonda, Sitapur, Rae Bareli and Barabanki ) were selected based upon the District Development Indices ${ }^{8}$ of Uttar Pradesh categorizing various districts of the state as developed, backward and most backward. These were selected through random sampling (Fish Bowl Method).

Stage II: Selection of one Tehsil of each District carried out through Random Sampling (Fish Bowl Method.)

Stage III: Selection of one Block in each Tehsil of each district again through Random Sampling.

Stage IV: Selection of two villages from each block one from the highest populated villages and another from the lowest populated villages through Random Sampling -Fish Bowl Method. Incorporating the findings from the pretesting stage, an Interview Schedule was worked out to gather responses from respondents across the four selected most backward districts of Central Uttar Pradesh. The 52-variable questionnaire sought to seek data regarding mobile usage acceptance and growth in areas relating to women's Safety, Information about government run helplines for women's safety and whether the rural populace was accepting of the new mobile technology and if penetration was deep enough to impact society as a whole. Care was kept to include women in the team of surveyors who effectively overcame the barriers to communication accosted by their male counterparts while attempting to seek responses from rural women during the verification of Interview Schedule.

\subsection{Coding:}

Data thus collected through the 52 variable Interview Schedule was coded using IBM software Statistical Product and Service Solutions (or Statistical Package for the Social Sciences) better known as SPSS to scientifically analyze the collected data. Widely used for statistical analysis in social science, SPSS is also used by market researchers, health researchers, survey companies, government, education researchers, marketing organizations, data miners and others. The original SPSS manual $^{13}$ has been described as one of "sociology's most influential books" for allowing ordinary researchers to do their own statistical analysis. Instead of Open-Ended Questions, Fixed-Alternative Questions were used mostly following simple dichotomy and thus requiring basic skills and eliminating any chance of bias or misrepresentation of data.

It was found that $42 \%$ of women in Uttar Pradesh were using mobiles the figures for males in the same category was around $54 \%$.

\section{DATA ANALYSIS \& INTERPRETATION OF FINDINGS}

Among the few parameters under study was the awareness of the main Helplines initiated by the state to stem eve teasing, harassment and crime against women. In this regard 1090 the Women's Powerline is the premier such initiative in the state by the state government. In the few years since its initiation over 6 lakh complaints have been sorted and it is reckoned as one of the most effective platforms. With an app that can be downloaded and used to file a complaint, it is slowly but surely taking strong strides towards women's empowerment. So the respondents were asked if they knew about the same.

TABLE 1: AWARENESS OF 1090 WOMEN'S HELPLINE

\begin{tabular}{cccc}
\hline Awareness of & Males & Females\% & Total \% \\
$\mathbf{1 0 9 0}$ & $\%$ & & \\
Yes & 61 & 54 & 60 \\
No & 39 & 46 & 40 \\
\hline
\end{tabular}

Interpretation of data: For a helpline that has been operational just a little over three years, the response in favour of 1090 was remarkable. $61 \%$ males and $54 \%$ females admitted to knowing about this helpline which is ensuring a prompt crackdown on gender offenders and eve teasers and providing victims access to justice.

TABLE 2: AwARENESS OF FREE AMBULANCE HELPLINE 102

\begin{tabular}{cccc}
\hline SMS/IVRS & $\begin{array}{c}\text { Males } \\
(\boldsymbol{\%})\end{array}$ & Females $(\%)$ & Total (\%) \\
Yes & 99.8 & 100 & 99.8 \\
No & 0.2 & 0 & 0.2 \\
\hline
\end{tabular}

Interpretation of data: Again a whopping majority of both men and women said aye to knowing about this very handy helpline operational in the state to provide free door to door access to health services for people in the state, especially 
those from the underprivileged sections of society. There is almost $100 \%$ awareness of the same in both men and women. TABLE 3: AWARENESS OF POLICE HELPLINE 100

\begin{tabular}{lccc}
\hline Helpine 100 & $\begin{array}{c}\text { Males } \\
(\boldsymbol{\%})\end{array}$ & Females (\%) & Total (\%) \\
Yes & 99.5 & 100 & 99.6 \\
No & 0.5 & 0 & 0.4 \\
\hline
\end{tabular}

Interpretation of data: A near $100 \%$ response across the two genders shows that where it comes to their security, the state's public is quick to adapt to helplines that ensure their safety and wellbeing.

TABLE 4: BEST COMMUNICATION TOOL

\begin{tabular}{lccc}
\hline $\begin{array}{c}\text { Best Communication } \\
\text { Tool }\end{array}$ & $\begin{array}{c}\text { Males } \\
(\boldsymbol{\%})\end{array}$ & $\begin{array}{c}\text { Females } \\
(\boldsymbol{\%})\end{array}$ & $\begin{array}{c}\text { Total } \\
(\boldsymbol{\%})\end{array}$ \\
Personal Interaction & 42.7 & 35.9 & 41.4 \\
Mobile Helpline/SMS & 40.0 & 44.9 & 40.8 \\
Folk methods or PA & 0.5 & 0 & 0.6 \\
Systems & & & \\
Pamphlet/Wall Writing & 1.2 & 3.5 & 1.6 \\
Email/Website & 15.6 & 15.7 & 15.6 \\
\hline
\end{tabular}

Interpretation of data: This was the trickiest of all the questions asked - to ascertain whether traditional preference for personal interaction is giving way to new media and its usage. Data derived clearly indicates that while Personal Interaction remains a hot favourite, other forms of communication using Mobiles Helpline/ SMS/ Emails and Websites have overtaken the same where it comes to most preferred communication tools. $44.4 \%$ men and $39.4 \%$ (Total $43 \%$ ) women voted in favour of traditional means of communication thus giving a clear majority to Modern Digital Communication tools ( $55.6 \% \mathrm{Men} / 50.6 \%$ Women and a total aggregate of $56.4 \%$ in favour)

\section{CONCLUSION}

Women are equally sensitized to the benefits of mobile usage and very adept at handling the same and also various applications that smartphones offer to mobile subscribers today. The research study conclusively proved the hypothesis that Mobile Media Penetration has resulted in a positive Social and Behavioural change among the rural population and there is large scale awareness about Women's Helplines, Free Ambulance Services and Police Helpline among people in the state who know which Helpline to use for what purpose and get relief for various distressing situations.

It was also found that Calling and SMS through mobiles have replaced traditional means of communication with over $50 \%$ majority. This was a very promising development as mobile communication can serve as a catalyst for rural development and targeted intervention through an integrated approach customized to suit the need of the sector, for both women and men. There is sufficient mobile penetration across both genders, even in the most backward districts of the state, to allow for a combined outreach endeavour with maximized impact through mobile helplines. Despite low literacy, simple
IVRS messages and text messages can be directly/ indirectly used for targeted intervention in rural societies.

Not only is there widespread usage of mobiles, there is also large scale acceptance for mobile communication and Information Dissemination and Consultative Processes can be accelerated through targeted intervention through usage of select consumer databases by SMS/IVRS which can be an effective means to bridge the information and access gap.

Most respondents have affirmed that they are open to the idea of being directly approached through mobile messaging/ calls /IVRS /Texts as this is the most efficient, swift and assured means of communication. Even women, who do not have independent access to phones, say that they have easy, unfettered and open access to mobiles owned by male members of the house.

Traditional communication mediums pale in comparison to the prompt efficient and direct contact that can be made through mobiles and this in today's day and age, is the best means of communication. In fact there is sufficient penetration of mobiles in the state to underscore the need to draft a state policy of the effective use of mobiles as a means of communication and information dissemination and take forward the consultative dialogue between the government and the public using mobiles as a cheap and effective means of communication. However, the one disappointing fact that did come to light was the huge gap in information dissemination with government operatives showing a very lackadaisical attitude towards using mobiles as a medium to communicate to their rural beneficiaries.

\section{RECOMMENDATIONS}

From the data collected, it can be easily seen that there is sufficient mobile penetration even in the most backward districts of the state to allow for integrated approach through mobile phones. Simple SMS/IVRS messages can be used for targeted intervention in rural areas. Thus mobile helplines to ascertain access to health, police and women's safety services have widespread acceptance and usage in the rural areas as well as urban areas. Most respondents have affirmed they are open to being contacted through mobile messaging/calling/IVRS as this is the swiftest, efficient and assured means of communication.

It is the apathetic attitude of government departments and their approach to information dissemination that has created a huge gap between target audience and information providers. Efficient use of mobile technology can effectively bridge this gap. A state policy can be envisaged to improve outreach and efficacy of government schemes using mobile phones

\section{REFERENCES}

[1] Brookings Report On 2014 Global Women In Leadership Conference, Johns Hopkins University, School of Advanced International Studies, April 4, 2014. http://www.brookings.edu/blogs/africa-infocus/posts/2014/04/18-women- mobile-technology-maretrakotondrazaka

[2] UNESCO : Empowering Women And Girls In Rural Areas Through Mobile Learning And Communication Available: http://www.unesco.org/new/en/unesco/themes/icts/m4ed/mobile-

learning- week/workshops/empowering-women-and-girls-in-rural-areas- 
through-mobile-learning-and-communication-the-cases-of-costa-ricaand-india/

[3] Mascontext: Communication As A Tool For Empowerment Issue 14/ Summer 12 http://www.mascontext.com/issues/14-communicationsummer- 12/communication-as-a-tool-for-empowerment/

[4] Eric Bellman, "Rural India Snaps Up Mobile Phones Demand Among Poor Farmers Keeps an Industry Growing as Other Sectors of the Economy Are Jolted," 2009 in Wall Street Journal report Avialable: http://www.wsj.com/articles/SB123413407376461353

[5] Ethinos Snapshot of Digital India March 2016 Available at http://www.slideshare.net/Ethinos/snapshot-of-digital-india-march-2016

[6] NASSCOM-AKAMAI Technologies Report "The Future of Internet in India"Available:

http://www.nasscom.in/sites/default/files/Article News/PR NASSCOM AKAMAI Rise\%20of\%20Internet 17082016.pdf

[7] Census of India 2011 Available at censusindia.gov.in

[8] District Development Indices, CGG Working Paper 2003 Available: http://www.cgg.gov.in/workingpapers/WP-156-178.pdf

[9] UNDP'S Human Development Report 2016 Available: http://hdr.undp.org/sites/default/files/2015_human_development_report. pdf

[10] Govt. Of India's Planning Commission Uttar Pradesh : State Development Report (Vol I \& II) [Online] Available: http://planningcommission.nic.in/plans/stateplan/index.php?state=sdr_u p.htm

[11] India Internet Landscape 2016 Available: http://www.slideshare.net/kingdevil/india-internet-presence-mobileinternet-usage-trend

[12] National Crime Records Bureau Report 2016 Available at ncrb.nic.in

[13] Nie, Bent \& Hull, "SPSS: Statistical Package for the Social Sciences", McGraw-Hill, 1970 